\title{
In vitro antiplasmodial evaluation of ethanolic and $n$-hexane extracts of Parinari curatellifolia stem bark
}

\author{
Babasoji P. OMONIWA ${ }^{1 *}$, Kunle OKAIYETO ${ }^{2}$, David O. OMONIWA ${ }^{3}$ and Olumuyiwa A. \\ OLORUNYOMI ${ }^{4}$
}
${ }^{1}$ Ethnopharmacology, Reproductive Biochemistry and Biochemical Toxicology Research Laboratory, Department of Science Laboratory Technology, Faculty of Natural Sciences, University of Jos, P.M.B. 2084, Jos. Nigeria. ${ }^{2}$ Applied and Environmental Microbiology Research Group (AEMREG), Department of Biochemistry and Microbiology, University of Forte Hare, Alice 5700, South Africa.
${ }^{3}$ Department of Veterinary Medicine, Surgery and Radiology, Faculty of Veterinary Medicine, University of Jos, Jos. Nigeria. ${ }^{4}$ Department of Biochemistry, Faculty of Basic Medical Sciences, University of Jos. Nigeria.

Received 22 ${ }^{\text {nd }}$ February 2021; Accepted $28^{\text {th }}$ April 2021

\begin{abstract}
Parinari curatellifolia and other Parinari species are used traditionally in many parts of Africa as a remedy for malaria among other diseases. To ascertain this folkloric claim, the antiplasmodial potential of ethanol extract of Parinari curatellifolia stem bark (EEPCSB) and n-hexane extract of Parinari curatellifolia stem bark (HEPCSB) on Plasmodium falciparum was studied. Parasites were grown in a 96-well plate containing Roswell Park Memorial Institute-1640. The wells were grouped into: control (untreated), artemether-treated, EEPCSB-treated and HEPCSBtreated groups. Treatments were administered to the tune of 10,20, 40 and $80 \mu \mathrm{g} / \mathrm{ml}$. Parasitemia was observed by microscopy after 24, 48 and 72h of incubation. EEPCSB and HEPCSB elicited dose and duration-dependent reduction $(\mathrm{p}<0.05)$ in parasitemia when compared with the untreated group. The recorded percentage parasite inhibition by the extracts was lower $(\mathrm{p}<0.05)$ when compared with artemether. There was no difference $(\mathrm{p}>0.05)$ in plasmodium lactate dehydrogenase activity of EEPCSB-treated and artemether-treated groups. Findings from this study show that extracts of $P$. curatellifolia stem bark, especially EEPCSB, demonstrated excellent inhibitory activities against $P$. falciparum and can be a good source of compounds for the development of novel antimalarial drugs.
\end{abstract}

Keywords: Parinari curatellifolia; Extracts; Plasmodium falciparum; Parasitemia; Antiplasmodial

\section{INTRODUCTION}

Malaria continues to be one of the most devastating infectious diseases with an estimated 228 million cases globally in 2019 [1]. Over the years, the prevalence of malaria has been increasing at a high rate, particularly in developing countries [2]. Nigeria being the most populated country in Africa has the highest prevalence of malaria cases in the
African region, possibly due to the climatic conditions, which encourage the rapid multiplication of the parasites [3]. About 60 million Nigerians have malaria more than once in a year, with pregnant women and children (under 5 years) being most susceptible to the attack due to their low resistance and therefore constitute majority of the cases [4].

*Correspondence. E-mail: sojiomoniwa@gmail.com Tel: +234-8037362620.

ISSN 0189-8442

2021. Published by Faculty of Pharmaceutical Sciences, University of Jos, Nigeria. Under Creative Commons Attribution-Non-Commercial 4.0 International License. https://creativecommons.org/licenses/by-nc/4.0/ 
Artemisinin, and quinine are commonly used as antimalarial drugs. However, plasmodium resistance to antimalarial therapies has posed serious risk to human health, so that the dream of malaria eradication appears to be a huge challenge. As a result, malaria remains one of the dreaded diseases facing the developing world [5]. Several efforts have been made towards discovering novel and active drugs in combating the multidrug-resistant parasites, therefore, much attention has been focused on validating the efficacy of commonly used folkloric herbs for the treatment of malaria in Africa [2]. It has been documented that the majority of the population in sub-Saharan Africa depend solely on folkloric medicine for their primary healthcare needs because of their accessibility, low cost, and socio-cultural background $[6,7]$.

Africa is greatly endowed with a wide diversity of plants. Folkloric herbs represent the core reservoir for the discovery of active ingredients for the development of effective and novel drugs that could be used in treating different human diseases $[8,9]$. The advent of phytochemistry and pharmaceutical chemistry have enhanced the ability to utilize active compounds isolated from plants, or their synthetic equivalents in medicine. This is mainly because of the broader degree of chemical diversity and novelty possessed by medicinal plants than any other source $[10$, 11]. It is generally known that the bioactive constituents of plant extracts vary with the solvent used in the extraction process [12]. As a result of their extensive history of use and the fact that they are an excellent source of therapeutic agents applicable in traditional medicine, searching for alternative potent antimalarial substances from natural products is a justifiable approach [13]. Several studies have been reported on the scientific in vitro or in vivo validation of natural products with significant antimalarial activities that could serve as a lead for the development of new and effective antiplasmodial drugs [7, 14, 15, 16, 17].

Parinari curatellifolia (Planth.ex
Benth) belongs
the Chrysobalanaceae family and genus Parinari [18]. It is widely distributed in south, north and central Africa [19]. It is also grown in Zuru and its environs in Northern Nigeria. $P$. curatellifolia is used in traditional medicine for the treatment of many diseases. The leaf extract is used as expectorant, sedative and in the treatment of anemia and inflammation while the fruit extract exhibit cardiotonic and diuretic properties [20]. Also, the bark extract is used for the treatment of cough, dandruff, itchy scalp and as vaginal douches [21]. Other traditional uses include treatment of cancer, pneumonia, fever, bacterial infections, constipation, hypertension, liver, and kidney-related problems and dressing of fracture/dislocation $[22,23,24,25,26,27]$. It was reported that aqueous fraction of $P$. curatellifolia at 2.8 $\mathrm{g} / 100 \mathrm{ml}$ showed significant inhibitory activity against Staphylococcus aureus and Klebsiella spp. while the methanolic extract at the same concentration was effective on Bacillus subtilis and Pseudomonas aeruginosa [2] .

Extensive effort is still needed in medicinal plant research to discover novel antimalarial agents [28, 29]. As a result, the present study is aimed at evaluating the in vitro antiplasmodial activity of the crude ethanolic and n-hexane extracts of $P$. curatellifolia stem bark.

\section{EXPERIMENTAL METHODS}

Plant material. The stem bark of $P$. curatellifolia was collected from Old Lamingo road, Jos, Plateau State, Nigeria in the month of June. Identification and authentication of the plant was carried out by Mr. O. E. Agyeno of the Herbarium of the Department of Plant Science and Biotechnology, Faculty of Natural Sciences, University of Jos, Nigeria. The plant specimen was deposited and the following voucher number obtained; UJH1600024. 
Experimental organism. Plasmodium falciparum was obtained from the blood of a certified $P$. falciparum-infected patient at GMedical and Diagnostic Centre, Jos, Plateau State, Nigeria, who had not received any antimalarial treatment 2 weeks prior to the time of blood collection. Five milliliters $(5 \mathrm{~mL})$ of blood was collected from the patient into EDTA bottles and subsequently centrifuged at $2000 \mathrm{rpm}$ for 10 minutes to separate the plasma from the red blood cell (RBC) pellets. The RBC pellets were thereafter washed in RPMI 16403 times before being used for parasite cultivation.

Ethical clearance. This research was carried out with utmost compliance with standards of research involving human as subjects. Ethical approval was granted by the Ethical Committee of G-Medical and Diagnostic Centre, Jos, Plateau State, Nigeria, and the research was allocated reference number GMD/0001034.

Chemicals and reagents. The culture medium (Roswell Park Memorial Institute (RPMI) 1640) was a product of Sigma-Aldrich Inc., Germany. Nitro blue tetrazolium/phenazine ethosulfate (NBT/PES) and Malstat reagent [Triton X-100, L-lactate, Tris buffer, APAD (3-acetyl pyridine adenine dinucleotide)] were products of Santa Cruz Biotechnology Ltd, Heidelberg, Germany. Other reagents were of analytical grade and were prepared in all glassdistilled water.

Preparation of ethanolic and n-hexane extracts of Parinari curatellifolia stem bark. Stem bark of $P$. curatellifolia were cut into pieces and oven-dried to constant weight at 45 ${ }^{\circ} \mathrm{C}$ for 14 days. The dried bark was then pulverized using an electric blender (Super Master ® Model SMB-2977). Sixty grams (60 g) of the powdered plant material was weighed into two separate beakers labelled A and B after which $500 \mathrm{ml}$ of ethanol and n-hexane were added to the respective beakers. The mixtures were stirred and left to stand for $48 \mathrm{~h}$ in a refrigerator for proper maceration and extraction after which they were filtered using Whatman No.1 filter paper and the filtrates concentrated on a water bath. The concentrates were thereafter reconstituted into the doses used in this experiment.

Secondary metabolites screening. Screening was carried out on EEPCSB and HEPCSB in order to ascertain the presence of some secondary metabolites. Specifically, the presence of alkaloids, tannins, and cardiac glycosides were determined by previously described methods [30]. Phenolics and flavonoids [31], saponins [32], terpenoids and steroids [33] and resins [34] were similarly determined using reported methods.

Parasite cultivation and assessment of in vitro antiplasmodial activity of extracts. The malaria parasites ( $P$. falciparum) hosted in human erythrocytes were cultured in $50 \mathrm{ml}$ of RPMI 1640 medium supplemented with $10 \mathrm{ml}$ of $0.5 \%$ Albumax II and $0.1 \mathrm{ml}$ gentamycin at $37{ }^{\circ} \mathrm{C}$ in an anaerobic jar. The culture $(100 \mu \mathrm{l})$ was transferred into different wells of a 96well plate and fresh uninfected RBCs at $1 \%$ hematocrit added. One hundred microliter (100 $\mu \mathrm{l})$ of EEPCSB, HEPCSB and artemether reconstituted in $5 \% \mathrm{v} / \mathrm{v}$ of dimethylsulfoxide at concentrations of $10,20,40$ and $80 \mu \mathrm{g} / \mathrm{ml}$ were then transferred into designated wells. Wells for the control groups were left untreated. The microtitre plate was subsequently incubated in an anaerobic jar at $37{ }^{\circ} \mathrm{C}$. Thick/thin film smears of incubated samples were made on well labelled, dry, grease-free slides by picking sample from each culture well at intervals of 24, 48 and $72 \mathrm{~h}$ and allowed to air dry. The films were then stained by sequential application of Field stain A and B. Microscopy was thereafter carried out to determine the parasitaemia. Cultures were maintained by adding $50 \mu 1$ of RPMI 1640 medium and fresh uninfected RBCs at $1 \%$ hematocrit after smear making to avoid drying and to ensure continuous and proper parasite growth. Parasitaemia was also expressed as percentage 
of total infected red blood cells over the total number of red blood cells counted for each smear. The average parasitaemia of the smear replicates for each concentration was calculated. Ten different fields were counted per slide. The percentage parasitaemia in each field was calculated using the formula:

$$
\begin{aligned}
& \% \text { Parasitemia } \\
& =\frac{\text { Number of infected blood cells }}{\text { Total red blood cells }} \times 100 \%
\end{aligned}
$$

Determination of percentage inhibition of $P$. falciparum by extracts. The percentage inhibition of the parasites by the extracts was calculated using the formula:

$\%$ Parasite inhibition $=$

$\frac{(\% \text { parasitemia of control-\% parasitemia of test) }}{\% \text { parasitemia of control }} \times 100 \%$

Determination of median inhibitory concentration (IC50) of extracts. The concentrations of the extracts required to inhibit parasite growth by $50 \%$ ( $\mathrm{IC}_{50}$ ) were determined by nonlinear regression analysis. The percentage parasite inhibition (on Y-axis) was plotted against the logarithm of extract concentrations (on $\mathrm{X}$-axis) and the $\mathrm{IC}_{50}$ values interpolated from the dose-response curve.

Assay of plasmodium lactate dehydrogenase activity. Plasmodium lactate dehydrogenase (pLDH) assay was carried out in 96-well microtitre plates as previously described [16]. Malstat reagent $(100 \mu \mathrm{L})$ was added to a new microtitre plate. Thereafter, $20 \mu \mathrm{L}$ of culture (as described in the antiplasmodial test above) after $72 \mathrm{~h}$ of incubation, was taken from each well and added to the corresponding well of the Malstat plate. NTB/PES $(25 \mu \mathrm{L})$ was then added to each well to initiate the LDH reaction. Colour development of the LDH plate was monitored and the absorbance was taken at 650 $\mathrm{nm}$ with the aid of a microplate reader (Molecular Devices Spectramax plus microplate spectrophotometer) after $45 \mathrm{~min}$ of incubation in the dark. Percentage pLDH activity and percentage $\mathrm{pLDH}$ inhibition were calculated as follows:

$$
\begin{aligned}
& \% \text { pLDH activity } \\
& =\frac{\text { Absorbance of test sample }}{\text { Absorbance of control }} \times 100 \% \\
& \% \text { pLDH inhibition }=100-\% \text { pLDH activity }
\end{aligned}
$$

Statistical analysis. Data are presented as mean (3 replicates) \pm Standard Deviation (SD). Data were subjected to statistical analysis using the Statistical Package for Social Sciences (SPSS) software version 20. All significant differences were determined by one-way analysis of variance (ANOVA) and Post Hoc multiple comparison was done using Duncan's multiple range test. Significance level was set at $\mathrm{p}<0.05$. $\mathrm{IC}_{50}$ was determined by nonlinear regression analysis using Graphpad Prism.

\section{RESULTS}

Secondary metabolites. Secondary metabolite constituents of EEPCSB and HEPCSB are presented in Table 1. EEPCSB and HEPCSB contain alkaloids, flavonoids, tannins, cardiac glycosides and balsams while saponins, terpenes/steroids, phenolics and resins which were absent in HEPCSB were detected in EEPCSB.

In vitro plasmodium falciparum parasitemia. In vitro Plasmodium falciparum parasitemia following treatment with EEPCSB and HEPCSB is presented in Table 2. EEPCSB and HEPCSB significantly reduced $(\mathrm{p}<0.05)$ parasitemia at the various concentrations and durations of the experiment when compared with the untreated group. However a significant reduction $(\mathrm{p}<0.05)$ in parasitemia in the artemether-treated groups was recorded when compared with the extract-treated groups. At $24 \mathrm{~h}$, there was no significant difference $(p>0.05)$ in the parasitemia of groups treated with 10 and $20 \mu \mathrm{g} / \mathrm{ml}$ of EEPCSB and that of group treated with 40 $\mu \mathrm{g} / \mathrm{ml}$ of HEPCCSB. At $48 \mathrm{~h}, 10 \mu \mathrm{g} / \mathrm{ml}$ of EEPCSB compared favourably with $10 \mu \mathrm{g} / \mathrm{ml}$ of HEPCSB, $20 \mu \mathrm{g} / \mathrm{ml}$ of EEPCSB compared favourably with 20 and $40 \mu \mathrm{g} / \mathrm{ml}$ of HEPCSB while $40 \mu \mathrm{g} / \mathrm{ml}$ of EEPCSB compared 
favourably with $80 \mu \mathrm{g} / \mathrm{ml}$ of HEPCSB. At 72 $\mathrm{h}, 10$ and $20 \mu \mathrm{g} / \mathrm{ml}$ of EEPCSB did not cause any significant variation $(\mathrm{p}>0.05)$ in parasitemia when compared with 40 and 80 $\mu \mathrm{g} / \mathrm{ml}$ of HEPCSB respectively.

In vitro percentage Plasmodium falciparum inhibition. Table 3 shows the in vitro percentage Plasmodium falciparum inhibition following administration of EEPCSB and HEPCSB. Artemether elicited a significantly higher $(\mathrm{p}<0.05)$ percentage parasite inhibition ability when compared with EEPCSB and HEPCSB. At $24 \mathrm{~h}$, there was no significant difference $(p>0.05)$ in the percentage parasite inhibition of the groups treated with 10 and 20 $\mu \mathrm{g} / \mathrm{ml}$ of EEPCSB when compared with those of groups treated with 20 and $40 \mu \mathrm{g} / \mathrm{ml}$ of HEPCSB respectively. Similarly, groups treated with 10 and $40 \mu \mathrm{g} / \mathrm{ml}$ of EEPCSB showed percentage parasite inhibition comparable with groups treated 40 and 80 $\mu \mathrm{g} / \mathrm{ml}$ of HEPCSB respectively at $72 \mathrm{~h}$.

Median inhibitory concentration (IC50). Median inhibitory concentration $\left(\mathrm{IC}_{50}\right)$ of EEPCSB and HEPCSB at $72 \mathrm{~h}$ is presented in Table 4. The values were interpolated from a nonlinear regression curve of $\log$ (concentration) versus parasite inhibition curve of EEPCSB and HEPCSB at $72 \mathrm{~h}$. Artemether, EEPCSB and HEPCSB gave $\mathrm{IC}_{50}$ values of $0.51,0.44$ and $3.08 \mu \mathrm{g} / \mathrm{ml}$ respectively. The $\mathrm{IC}_{50}$ of EEPCSB is close to that of artemether while that of HEPCSB does not compare favourably with artemether.
Percentage Plasmodium lactate dehydrogenase activity and inhibition. Tables 5 and 6 represent percentage pLDH activity and percentage pLDH activity inhibition respectively following treatment with EEPCSB and HEPCSB. There was no significant difference $(p>0.05)$ in percentage pLDH activity and inhibition of the artemether-treated groups when compared with the EEPCSB-treated groups. However the groups treated with the HEPCSB exhibited a significantly higher $(\mathrm{p}<0.05) \mathrm{pLDH}$ activity and a corresponding significantly lower $(\mathrm{p}<$ 0.05) percentage pLDL inhibition when compared with the artemether and EEPCSBtreated groups.

\section{DISCUSSION}

Parinari curatellifolia is employed across Africa for the traditional treatment of a variety of diseases [21, 23]. These medicinal applications can be attributed to the presence of a vast array of secondary metabolites. As a result of the urgent need to discover new antimalarial drugs, it is necessary to consider this plant, which has numerous medicinal uses and a widespread African presence. The secondary metabolite constituents of the EEPCSB recorded in this study corroborate the result of a previous report, except for flavonoids which was reportedly absent in that work [35]. These metabolites may be responsible for the anti-plasmodial activities of the extracts.

Table 1: Secondary metabolite constituents of ethanolic and n-hexane extracts of Parinari curatellifolia stem bark

\begin{tabular}{ccc}
\hline Secondary metabolites & EEPCSB & HEPCSB \\
\hline Alkaloids & + & + \\
Flavonoids & + & + \\
Tannins & + & + \\
Saponins & + & - \\
Terpenoids & + & - \\
Steroids & + & - \\
Cardiac glycosides & + & + \\
Phenolics & + & - \\
Resins & + & - \\
\hline
\end{tabular}

$+=$ Present; - = Absent $\quad$ EEPCSB: Ethanolic extract of Parinari Curatellifolia stem bark HEPCSB: n-hexane extract of Parinari Curatellifolia stem bark 
Table 2: In vitro plasmodium falciparum parasitemia following treatment with ethanolic and $\mathrm{n}$-hexane extracts of Parinari curatellifolia stem bark

\begin{tabular}{|c|c|c|c|c|}
\hline Treatment & $\begin{array}{l}\text { Concn. } \\
(\mu \mathrm{g} / \mathrm{ml})\end{array}$ & $\begin{array}{c}\text { Parasitemia at } 24 \mathrm{~h} \\
(\% \text { parasitemia })\end{array}$ & $\begin{array}{c}\text { Parasitemia at } 48 \mathrm{~h} \\
(\% \text { parasitemia })\end{array}$ & $\begin{array}{l}\text { Parasitemia at } 72 \mathrm{~h} \\
(\% \text { parasitemia })\end{array}$ \\
\hline Control & - & $172.67 \pm 1.15^{\mathrm{a}}(57.53)$ & $192.33 \pm 1.15^{\mathrm{a}}(64.07)$ & $220.00 \pm 1.00^{\mathrm{a}}(88.37)$ \\
\hline Artemether & 10 & $4.67 \pm 0.58^{\mathrm{b}}(1.50)$ & $3.67 \pm 0.58^{\mathrm{b}}(1.20)$ & $1.67 \pm 0.03^{\mathrm{b}}(0.67)$ \\
\hline Artemether & 20 & $3.00 \pm 0.20^{\mathrm{c}}(1.00)$ & $1.67 \pm 0.43^{\mathrm{c}}(0.50)$ & $0.67 \pm 0.02^{\mathrm{c}}(0.27)$ \\
\hline Artemether & 40 & $2.33 \pm 0.38^{\mathrm{d}}(0.73)$ & $1.00 \pm 0.05^{\mathrm{d}}(0.30)$ & $0.00 \pm 0.00^{\mathrm{d}}(0.00)$ \\
\hline Artemether & 80 & $1.33 \pm 0.28^{\mathrm{e}}(0.40)$ & $0.33 \pm 0.05^{\mathrm{e}}(0.10)$ & $0.00 \pm 0.00^{\mathrm{d}}(0.00)$ \\
\hline EEPCSB & 10 & $124.67 \pm 1.15^{f}(42.83)$ & $112.67 \pm 2.08^{\mathrm{f}}(37.53)$ & $65.00 \pm 2.00^{\mathrm{e}}(26.00)$ \\
\hline EEPCSB & 20 & $124.33 \pm 0.58^{\mathrm{f}}(41.40)$ & $107.67 \pm 1.53^{\mathrm{g}}(35.87)$ & $59.33 \pm 1.53^{\mathrm{f}}(23.83)$ \\
\hline EEPCSB & 40 & $117.00 \pm 2.00^{\mathrm{g}}(38.97)$ & $100.00 \pm 2.00^{\mathrm{h}}(33.63)$ & $50.33 \pm 1.53^{\mathrm{g}}(20.23)$ \\
\hline EEPCSB & 80 & $111.33 \pm 1.53^{\mathrm{h}}(37.07)$ & $91.33 \pm 2.08^{\mathrm{i}}(30.40)$ & $42.08 \pm 1.00^{\mathrm{h}}(16.90)$ \\
\hline HEPCSB & 10 & $140.00 \pm 1.00^{\mathrm{i}}(46.33)$ & $115.00 \pm 3.50^{\mathrm{f}}(38.30)$ & $85.00 \pm 2.00^{\mathrm{i}}(34.20)$ \\
\hline HEPCSB & 20 & $132.33 \pm 0.58^{\mathrm{j}}(41.10)$ & $109.67 \pm 0.58^{\mathrm{g}}(36.50)$ & $74.00 \pm 1.53^{\mathrm{j}}(29.93)$ \\
\hline HEPCSB & 40 & $126.67 \pm 1.00^{f}(41.97)$ & $105.50 \pm 3.00^{\mathrm{g}}(34.97)$ & $65.33 \pm 1.53^{\mathrm{e}}(26.33)$ \\
\hline HEPCSB & 80 & $120.33 \pm 0.58^{\mathrm{k}}(40.10)$ & $100.00 \pm 1.00^{\mathrm{h}}(33.30)$ & $58.33 \pm 0.58^{\mathrm{f}}(19.43)$ \\
\hline
\end{tabular}

EEPCSB: ethanolic extract of Parinari curatellifolia stem bark, HEPCSB: n-hexane extract of Parinari curatellifolia stem bark, Values are means (of 3 replicates) \pm SD. Values with different superscripts down the column are significantly different $(\mathrm{p}<0.05)$.

Table 3: In vitro percentage plasmodium falciparum inhibition following administration of ethanolic and n-hexane extracts of Parinari curatellifolia stem bark

\begin{tabular}{ccccc}
\hline Treatment & Concn. $(\mu \mathrm{g} / \mathrm{ml})$ & $24 \mathrm{~h}$ & $48 \mathrm{~h}$ & $72 \mathrm{~h}$ \\
\hline Artemether & 10 & $97.39 \pm 0.29^{\mathrm{a}}$ & $98.13 \pm 0.29^{\mathrm{a}}$ & $99.24 \pm 0.30^{\mathrm{a}}$ \\
Artemether & 20 & $98.26 \pm 0.10^{\mathrm{b}}$ & $99.22 \pm 0.29^{\mathrm{b}}$ & $99.69 \pm 0.28^{\mathrm{a}}$ \\
Artemether & 40 & $98.73 \pm 0.40^{\mathrm{bc}}$ & $99.53 \pm 0.05^{\mathrm{b}}$ & $100.00 \pm 0.00^{\mathrm{a}}$ \\
Artemether & 80 & $99.30 \pm 0.29^{\mathrm{c}}$ & $99.84 \pm 0.19^{\mathrm{b}}$ & $100.00 \pm 0.00^{\mathrm{a}}$ \\
EEPCSB & 10 & $25.55 \pm 1.05^{\mathrm{d}}$ & $41.42 \pm 1.00^{\mathrm{c}}$ & $70.58 \pm 0.85^{\mathrm{b}}$ \\
EEPCSB & 20 & $28.04 \pm 0.35^{\mathrm{e}}$ & $44.01 \pm 0.45^{\mathrm{d}}$ & $73.03 \pm 0.70^{\mathrm{c}}$ \\
EEPCSB & 40 & $32.26 \pm 1.23^{\mathrm{f}}$ & $47.51 \pm 1.72^{\mathrm{e}}$ & $77.11 \pm 0.70^{\mathrm{d}}$ \\
EEPCSB & 80 & $35.56 \pm 1.25^{\mathrm{g}}$ & $52.55 \pm 0.85^{\mathrm{f}}$ & $80.88 \pm 0.49^{\mathrm{e}}$ \\
HEPCSB & 10 & $19.47 \pm 1.12^{\mathrm{h}}$ & $40.22 \pm 1.31^{\mathrm{c}}$ & $61.30 \pm 1.01^{\mathrm{f}}$ \\
HEPCSB & 20 & $26.56 \pm 1.50^{\mathrm{d}}$ & $43.03 \pm 0.55^{\mathrm{d}}$ & $66.13 \pm 0.86^{\mathrm{g}}$ \\
HEPCSB & 40 & $27.05 \pm 0.30^{\mathrm{e}}$ & $45.42 \pm 0.64^{\mathrm{e}}$ & $70.25 \pm 0.78^{\mathrm{b}}$ \\
HEPCSB & 80 & $30.30 \pm 0.23^{\mathrm{i}}$ & $48.03 \pm 0.77^{\mathrm{e}}$ & $78.10 \pm 0.38^{\mathrm{d}}$ \\
\hline
\end{tabular}

EEPCSB: ethanolic extract of Parinari curatellifolia stem bark, HEPCSB: $n$-hexane extract of Parinari curatellifolia stem bark, Values are means (of 3 replicates) \pm SD. Values with different superscripts down the column are significantly different $(\mathrm{p}<0.05)$.

Table 4: Median inhibition concentrations $\left(\mathrm{IC}_{50}\right)$ of ethanolic and n-hexane extracts of Parinari curatellifolia stem bark at 72 hours.

\begin{tabular}{ccc}
\hline Artemether $(\mu \mathrm{g} / \mathrm{ml})$ & EEPCSB $(\mu \mathrm{g} / \mathrm{ml})$ & HEPCSB $(\mu \mathrm{g} / \mathrm{ml})$ \\
\hline 0.51 & 0.44 & 3.08 \\
\hline
\end{tabular}

EEPCSB: Ethanolic extract of P. curatellifolia stem bark, HEPCSB: n-hexane extract of $P$. curatellifolia stem bark. 
Table 5: Percentage plasmodium lactate dehydrogenase activity 72 hours after administration of ethanolic and nhexane extracts of Parinari curatellifolia stem bark

\begin{tabular}{ccc}
\hline Treatment & Concn. $(\mu \mathrm{g} / \mathrm{ml})$ & LDH activity \\
\hline Artemether & 10 & $50.31 \pm 5.55^{\mathrm{a}}$ \\
Artemether & 20 & $47.48 \pm 5.85^{\mathrm{a}}$ \\
Artemether & 40 & $45.44 \pm 5.36^{\mathrm{a}}$ \\
Artemether & 80 & $40.51 \pm 9.63^{\mathrm{a}}$ \\
EEPCSB & 10 & $52.02 \pm 7.48^{\mathrm{a}}$ \\
EEPCSB & 20 & $50.91 \pm 4.66^{\mathrm{a}}$ \\
EEPCSB & 40 & $49.75 \pm 3.73^{\mathrm{a}}$ \\
EEPCSB & 80 & $43.98 \pm 4.95^{\mathrm{a}}$ \\
HEPCSB & 10 & $75.56 \pm 4.21^{\mathrm{b}}$ \\
HEPCSB & 20 & $73.39 \pm 1.69^{\mathrm{b}}$ \\
HEPCSB & 40 & $70.28 \pm 2.99^{\mathrm{bc}}$ \\
HEPCSB & 80 & $65.72 \pm 3.14^{\mathrm{c}}$ \\
\hline
\end{tabular}

EEPCSB: Ethanolic extract of Parinari curatellifolia stem bark, HEPCSB: n-hexane extract of Parinari curatellifolia stem bark, LDH: Lactate dehydrogenase. Values are means (of 3 replicates) \pm SD. Values with different superscripts down the column are significantly different $(\mathrm{p}<0.05)$

Table 6: Percentage plasmodium lactate dehydrogenase inhibition 72 hours after administration of ethanolic and nhexane extracts of Parinari curatellifolia stem bark

\begin{tabular}{ccc}
\hline Treatment & Concn. $(\mu \mathrm{g} / \mathrm{ml})$ & LDH activity \\
\hline Artemether & 10 & $49.69 \pm 5.55^{\mathrm{a}}$ \\
Artemether & 20 & $52.52 \pm 5.85^{\mathrm{a}}$ \\
Artemether & 40 & $54.56 \pm 5.36^{\mathrm{a}}$ \\
Artemether & 80 & $59.49 \pm 9.63^{\mathrm{a}}$ \\
EEPCSB & 10 & $47.98 \pm 7.48^{\mathrm{a}}$ \\
EEPCSB & 20 & $49.09 \pm 4.66^{\mathrm{a}}$ \\
EEPCSB & 40 & $50.25 \pm 3.73^{\mathrm{a}}$ \\
EEPCSB & 80 & $56.02 \pm 4.95^{\mathrm{a}}$ \\
HEPCSB & 10 & $24.44 \pm 4.21^{\mathrm{b}}$ \\
HEPCSB & 20 & $26.61 \pm 1.69^{\mathrm{b}}$ \\
HEPCSB & 40 & $29.72 \pm 2.99^{\mathrm{bc}}$ \\
HEPCSB & 80 & $34.28 \pm 3.14^{\mathrm{c}}$ \\
\hline
\end{tabular}

EEPCSB: Ethanolic extract of Parinari curatellifolia stem bark, HEPCSB: n-hexane extract of Parinari curatellifolia stem bark, LDH: Lactate dehydrogenase. Values are means (of 3 replicates) \pm SD. Values with different superscripts down the column are significantly different $(p<0.05)$

For instance, alkaloids; (+)-Nmethyliscoclaurine, atherosperminine and 2hydroxy-atherosperminine, isolated from bark of Cryptocarya nigra have been reported to elicit strong antiplasmodial activity against Plasmodium falciparum [36]. Similarly, flavonoids (artocarpesin, artochamin C and kushenol E) isolated from Morus mesozygia were also reported to demonstrate considerable antiplasmodial activity against chloroquine resistant FcB1 Plasmodium falciparum strain [37]. Recently, some compounds have been isolated from different parts of $P$. curatellifolia. For example, $\beta$-sitosterol which was isolated from the leaves of $P$. curatellifolia was reported to reduce the growth of Candida 
krusei by $83 \%$ [38] while toddalolactone and 10-hydroxy-13-methoxy-9-methyl-15-oxo-

20-norkaur-16-en-18-oic acid 1-lactone isolated from the root of $P$. curatellifolia demonstrated antimicrobial activity against Candida albicans, Cryptococcus neoformans and Aspergillus niger [39]. These compounds may also exhibit antiplasmodial activity against $P$. falciparum and may be responsible for the antiplasmodial activity of this plant recorded in this study.

The percentage parasite inhibition recorded following administration of the extracts which was calculated from the parasitemia revealed that both extracts inhibited $P$. falciparum growth in a dose and duration-dependent manner. The EEPCSB however exhibited a higher parasite inhibition activity than the HEPCSB. Some of the secondary metabolites contained in the ethanolic extract (i.e. saponins, terpenoids, steroids, resins and phenolics) but absent in the n-hexane extract might be responsible for the higher anti-plasmodial activity recorded with the EEPCSB. For example, two triterpenoid saponins, namely $16-\mathrm{O}-(\beta$-arabinopyranosyl)3-oxo-12, 16 $\beta$, 21 $\beta$, 22-tetrahydroxyhopane and $16-\mathrm{O}-(\beta$-arabinopyranosyl)-3-oxo- 12 , $16 \beta$, 22-trihydroxyhopane isolated from the aerial parts of Glinus oppositifolius were reported to exhibit in vitro anti-plasmodial activity against Plasmodium falciparum [40].

Plant extracts, according to their activities against $P$. falciparum, are categorized as promising ( $\mathrm{IC}_{50}<10 \mu \mathrm{g} / \mathrm{ml}$ ), moderate (IC 5010 - $20 \mu \mathrm{g} / \mathrm{ml}$ ), good (IC 5020 $40 \mu \mathrm{g} / \mathrm{ml}$ ), marginally potent (IC 5040 - 70 $\mu \mathrm{g} / \mathrm{ml}$ ) and poor ( $\mathrm{IC}_{50}>70 \mu \mathrm{g} / \mathrm{ml}$ ) [41]. In this study, $\mathrm{IC}_{50}$ of the extracts after $72 \mathrm{~h}$ revealed that both extracts can be categorized as having promising anti-plasmodial activities, with the EEPCSB showing comparable antiplasmodial activity with artemether. The $\mathrm{IC}_{50}$ values for the ethanolic and n-hexane extracts of $P$. curatellifoila in this study is not comparable with previous reports $[42,43]$. Karou et al. had reported an $\mathrm{IC}_{50}$ value of $>100 \mu \mathrm{g} / \mathrm{ml}$ for methanol extract of aerial parts of this plant while Clarkson et al. similarly reported a higher $\mathrm{IC}_{50}$ value $(17 \mu \mathrm{g} / \mathrm{ml})$ for dichloromethane extract of leaves/flowers of this plant, both against $P$. falciparum. This suggests that the stem bark of $P$. curatellifolia may contain more potent antiplasmodial activity than the other parts of the plant reported by these researchers. It is also possible that the extraction solvents, ethanol and n-hexane, used in this work, were able to extract more of the antiplasmodial principles than those used in the previous works cited. $\mathrm{IC}_{50}$ values in this study predict the presence of two very potent antiplasmodial agents in the stem bark of $P$. curatellifolia, one polar and the other very non-polar.

The concentration of $\mathrm{pLDH}$ produced by the cultured parasites was also employed for the determination of extracts anti-plasmodial activity. The fact that $\mathrm{pLDH}$ is distinguishable from host $\mathrm{LDH}$ makes it suitable as an indicator of malaria parasite presence with its concentration correlating with parasite density [44]. In this study both EEPCSB and HEPCSB exhibited profound pLDH-inhibitory ability and favourably compare with artemether. This inhibition of $\mathrm{pLDH}$ activity translates to parasite reduced ability or inability to regenerate nicotinamide adenine dinucleotide (NAD) for continuous influx of glucose through the Embden-Meyerhof pathway [45]. Consequently, there is a cut off of parasite energy source, which results in parasite death.

In conclusion, both extracts displayed promising anti-plasmodial activity against blood stage $P$. falciparum with EEPCSB eliciting a higher activity than HEPCSB. The outstanding antiplasmodial activity exhibited by EEPCSB calls for further studies on the isolation of pure compounds responsible for the biological activity. It is believed that EEPCSB will serve as a starting point for the development of a new antimalarial drug. 
B.P. Omoniwa et al. / J. Pharmacy \& Bioresources 18(2), 103-112 (2021)

\section{REFERENCES}

1. World Health Organization. World malaria report 2019. Geneva: World Health Organization; 2019. https://www.who.int/malaria/publications/worldmalaria-report-2019/en/.

2. Lawal B, Ossai PC, Shittu OK, Abubakar AN, Ibrahim AM. Evaluation of Phytochemicals, Proximate, Minerals and Anti-nutritional Compositions of Yam Peel, Maize Chaff and Cean Coat. Inter J Appl Biol Res. 2014; 6 (2):01-17.

3. Aregawi M, Cibulskis RE, Otten M, Williams R. World malaria report 2009. World Health Organization; 2009.

4. Kahleen PT, Arthur T. Plasmodium, the agent of malaria. Foundation of Microbiology. 3rd ed. USA: WCBMcGRAW Hill Publishers. 1999:730-732.

5. World Health Organization. Fact Sheet on the World Malaria Report 2014; 2014. Retrieved from http://www.who.int/malaria/media/world_malaria_repo rt_2014/en/.

6. Yineger H, Yewhalaw D, Teketay D. Ethnomedicinal Plant Knowledge and Practice of the Oromo Ethnic Group in Southwestern Ethiopia. J. Ethnobiol Ethnomed. 2008; 4 (1):1-0. https://doi.org/10.1186/1746-4269-411.

7. Satish PV, Sunita K. Antimalarial efficacy of Pongamia pinnata (L) Pierre against Plasmodium falciparum (3D7 strain) and Plasmodium berghei (ANKA). BMC Compl Alternative Med. 2017; 17 (1):1-26. DOI 10.1186/s12906-017-1958-y.

8. Kaushik NK, Bagavan A, Rahuman AA, Mohanakrishnan D, Kamaraj C, Elango G, Zahir AA, Sahal D. Antiplasmodial Potential of Selected Medicinal Plants from Eastern Ghats of South India. Exp. Parasitol. 2013; $134 \quad$ (1):26-32. DOI: $10.1016 /$ j.exppara.2013.01.021

9. Abdissa D, Geleta G, Bacha K, Abdissa N. Phytochemical Investigation of Aloe pulcherrima Roots and Evaluation for its Antibacterial and Antiplasmodial Activities. PLoS One. 2017; 23:12 (3):e0173882. https://doi.org/10.1371/journal.pone.0173882.

10. Harvey A. The Continuing Value of Natural Products to Drug Discovery. GIT Lab. J. 2001; 5 (6):284-285.

11. Chin YW, Balunas MJ, Chai HB, Kinghorn AD. Drug Discovery from Natural Sources. The AAPS J. 2006; 8 (2):E239-53. doi: 10.1007/BF02854894.

12. Tijjani MB, Bello IA, Aliyu AB, Olurishe T, Maidawa SM, Habila JD, Balogun EO. Phytochemical and Antibacterial Studies of Root Extract of Cochlospermum tinctorium A. Rich. (Cochlospermaceae). Res. J. Med. Plant. 2009; 3 (1):16-22. DOI: 10.3923/rjmp.2009.16.22

13. Wink M. Modes of Action of Herbal Medicines and Plant Secondary Metabolites. Medicines. 2, 251286. DOI: $10.3390 /$ medicines2030251.
14. Lasisi AA, Olayiwola MA, Balogun SA, Akinloye OA, Ojo DA. Phytochemical Composition, Cytotoxicity and in vitro Antiplasmodial Activity of Fractions from Alafia barteri olive (Hook F. Icon)Apocynaceae. J. Saudi Chem. Soc. 2016; 20(1):2-6. https://doi.org/10.1016/j.jscs.2012.05.003

15. Okokon JE, Obot AU, Mohanakrishnan D, Mittal G, Sahal D. Antimalarial and Antiplasmodial Activity of Leaf Extract of Alchornea laxiflora. J. Herbs, Spices Med. Plants. 2017; 23(2):128-141. https://doi.org/10.1080/10496475.2016.1275072.

16. Omoniwa BP, Johnson TO, Soji-Omoniwa O, Gurumtet I, Manzah RA. In vitro Antiplasmodial Activity of Aqueous Extracts of Ochna schweinfurthiana Leaf on Plasmodium falciparum. JPB. 2017; 14 (2):269278. https://dx.doi.org/10.4314/jpb.v14i2.22

17. Mbouna CD, Kouipou RM, Keumoe R, Tchokouaha LR, Fokou PV, Tali BM, Sahal D, Boyom FF. Potent Antiplasmodial Extracts and Fractions from Terminalia mantaly and Terminalia superba. Malar. J. 2018; 17 (1):1-9. https://doi.org/10.1186/s12936-0182298-1.

18. Gororo M, Chimponda T, Chirisa E, Mukanganyama S. Multiple Cellular Effects of Leaf Extracts from Parinari curatellifolia. BMC Complement. Altern. Med. 2016; 16 (1):1-4. DOI 10.1186/s12906016-1287-6.

19. Mark H, Bart W. Flora of Zimbabwe: Species information: $\quad P$. curatellifolia. 2002. www,Zimbabwe.co.Zw/species data/species.

20. Peni IJ, Elinge CM, Yusuf H, Itodo AU, Agaie BM, Mbongo AN, Chogo E. Phytochemical Screening and Antibacterial Activity of Parinari curatellifolia Stem Extract. J. Med. Plant Res. 2010; 4 (20):20992102.

21. Qasem JR, Aau-Blan HA. Fungicidal Activity of Some Common Weed Extracts against Different Plant Pathogenic Fungi. J. Phytopathology. 1996; 144 (3):157161. http://dx.doi.org/10.1111/j.14390434.1996.tb01507.x.

22. Kraft C, Jenett-Siems K, Siems K, Jakupovic J, Mavi S, Bienzle U, Eich E. In vitro Antiplasmodial Evaluation of Medicinal Plants from Zimbabwe. Phytother. Res. 2003; 17 (2):123-128. doi: 10.1002/ptr.1066.

23. Ogbonnia SO, Olayemi SO, Anyika EN, Enwuru VN, Poluyi OO. Evaluation of Acute Toxicity in Mice and Subchronic Toxicity of Hydroethanolic Extract of Parinari curatellifolia Planch (Chrysobalanaceae) Seeds in Rats. Afr. J. Biotechnol. 2009; 8 (9):1800 - 1806.

24. Maroyi A. An Ethnobotanical Survey of Medicinal Plants Used by the People in Nhema Communal Area, Zimbabwe. J. Ethnopharmacol. 2011; 136(2):347-354. DOI: 10.1016/j.jep.2011.05.003. 
25. More G, Tshikalange TE, Lall N, Botha F, Meyer JJ. Antimicrobial Activity of Medicinal Plants against Oral Microorganisms. J. Ethnopharmacol. 2008; 119 (3):473-477. doi:10.1016/j.jep.2008.07.001.

26. Wurochekke AU, Eze HT, Nelson K. Effect of Methanolic Leaf Extract of Parinari curatellifolia on Rat Liver and Kidney. Sky J. Biochem. Res. 2013; 2 (7):4749.

27. Olaleye MT, Amobonye AE, Komolafe K, Akinmoladun AC. Protective Effects of Parinari curatellifolia Flavonoids against Acetaminopheninduced Hepatic Necrosis in Rats. Saudi J. Biol. Sci. 2014; 21(5):486-492. doi: 10.1016/j.sjbs.2014.06.005.

28. Elujoba AA. Book review: Traditional Medicinal Plants and Malaria. Afri. J. Tradit. Complement. Alterna. Med.2005:2: 206 - 207.

29. Akinjogunla OJ, Ekoi O, Odeyemi AT, Odeyemy A. Phytochemical Screening and in vitro Antibacterial Assessment of Aqueous Leaf Extracts of Vernonia amygdalina (Asteraceae) and Ocimum gratissimum (Lamiaceae) on Moxifloxacin-resistant Escherichia coli Isolated from Clinical and Environmental Samples. Nat. Sci. 2011; 9 (7):42-52.

30. Evans WC. Trease and Evans' Pharmacognosy. 13th Edition. London. Bailliere Tindall. 1989.

31. Odebiyi OO, Sofowora EA. Phytochemical Screening of Nigerian Medicinal Plants II. Lloydia. 1978; 41 (3):234-246.

32. Kokate CK.. Practical Pharmacognosy. New Delhi. Vallabh Prakashan. 1994. 107 - 113.

33. Gul R, Jan SU, Faridullah S, Sherani S, Jahan N. Preliminary Phytochemical Screening, Quantitative Analysis of Alkaloids, and Antioxidant Activity of Crude Plant Extracts from Ephedra intermedia indigenous to Balochistan. Sci. World J. 2017; 2017. https://doi.org/10.1155/2017/5873648.

34. Keo S, Meng C, Oeung S, Nov V, Lon SA, Vichet T, Va T, Sourn M, Chea S. Preliminary Phytochemical Screening of Selected Medicinal Plants of Cambodia. Asian J. Pharmacogn. 2017; 1(4):16-23.

35. Sylvanus U, Olakunle F, Amos J, Olutayo O. Antibacterial Activity and Phytochemical Evaluation of the Leaf, Root and Stem Bark Extracts of Parinari curatellifolia (planch. Ex benth). Int. J. Adv. Chem. 2014; 2:178-

81.http://dx.doi.org/10.14419/ijac.v2i2.3568.

36. Nasrullah AA, Zahari A, Mohamad J, Awang K. Antiplasmodial Alkaloids from the Bark of Cryptocarya nigra (Lauraceae). Molecules. 2013; 18(7):8009 - 80017. https://doi.org/10.3390/molecules18078009.
37. Zelefack F, Guilet D, Valentin A, Fongang R, Kom B, Chevalley S, Ngouela S, Tsamo E, Fabre N, Dijoux-Franca MG. Antiplasmodial and Cytotoxic Activities of Flavonoids and Arylbenzofuran Derivatives from Morus mesozygia. Greener J. Biol. Sci. 2012; 2(2):20 - 24.

38. Mawire P, Mozirandi W, Heydenreich M, Chi GF, Mukanganyama S. Isolation and Antimicrobial Activities of Phytochemicals from Parinari curatellifolia (Chrysobalanaceae). Adv. Pharmacol. Sci. 2021. Article ID 8842629, 18 pages. https://doi.org/10.1155/2021/8842629.

39. Mbunde MVN, Innocent E, Mabiki F, Andersson PG. In vitro Study for Antifungal Compounds from Parinari curatellifolia (Chrysobalanaceae) and Terminalia sericea (Combretaceae). Int. J. Biol. Chem. Sci. 2021; 15 (1): 367-378.

40. Traore F, Faure R, Ollivier E, Gasquet M, Azas N, Debrauwer L, Keita A, Timon-David P, Balansard G. Structure and Antiprotozoal Activity of Triterpenoid saponins from Glinus oppositifolius. Planta Med. 2000; 66(04):368-371. DOI: 10.1055/s-2000-8551.

41. Kamaraj C, Kaushik NK, Mohanakrishnan D, Elango G, Bagavan A, Zahir AA, Rahuman AA, Sahal D. Antiplasmodial Potential of Medicinal Plant Extracts from Malaiyur and Javadhu Hills of South India. Parasitol. Res. 2012; 111(2):703-715. DOI: $\underline{10.1007 / \mathrm{s} 00436-011-2457-6}$.

42. Karou SD, Tchadjobo T, Ouattara L, Anani K, Savadogo A, Agbonon A, Attaia MB, de Souza C, Sakly M, Simpore J. Antimicrobial, Antiplasmodial, Haemolytic and Antioxidant Activities of Crude Extracts from Three Selected Togolese Medicinal Plants. Asian Pacific J. Trop. Med. 2011; $808-813$.

43. Clarkson C, Maharaj VJ, Crouch NR, Grace OM, Pillay P, Matsabisa MG, Bhagwandin N, Smith PJ, Folb PI. In vitro Antiplasmodial Activity of Medicinal Plants Native to or Naturalized in South Africa. $J$. Ethnopharmacol. 2004; 92 (2004): 177 - 191.

44. Makler MT, Hinrichs DJ. Measurement of the Lactate Dehydrogenase Activity of Plasmodium falciparum as an Assessment of Parasitemia. Am. J. Trop. Med. Hyg. 1993; 48 (2):205-210. DOI: $10.4269 /$ ajtmh.1993.48.205.

45. Noedl H, Wongsrichanalai C, Wernsdorfer WH. Malaria Drug-sensitivity Testing: New Assays, New Perspectives. Trends Parasitol. 2003; 19 (4):175-181. DOI: 10.1016/s1471-4922(03)00028-X. 